According to Morin's judgment, the new element in the "sapiens" superior aptitudes and abilities is to picture and to sepulcher - the initial landmark of intelligent activity. The painting, with its significances, is able to reflect a language form, that remit to a different time to the present instant, and the sepulture shows that spirituality emerges in the human mind, for the new life post-mortem condition, where the deceased personality is preserved. Following this idea, we can infer that the greatest rational nature's expression is to determine the personal identity and this determination includes increase of corporal clothing and ornamentation.

Key-words: body, identity, chothing. 


\section{A forma idealizada do eu}

Miriam da Costa Manso MOREIRA DE MENDONÇA

Segundo as conclusões de Morin, o elemento novo no conjunto de aptidões e habilidades superiores do sapiens está na pintura e na sepultura, que constituem o marco inicial de sua atividade inteligente. A pintura, repleta de significados, pode ser considerada como uma forma de linguagem, que se remete a um tempo diferente do presente, e a sepultura mostra que a espiritualidade surge no seio da mente humana, pela crença em uma nova vida, após a morte, em que a identidade do morto seria preservada. Seguindo essa idéia, é possível deduzir que a maior expressão da natureza pensante reside na sua capacidade de definir essa identidade e tal individualização passa pelo acréscimo de roupas e ornamentos ao corpo.

Palavras-chave: corpo, identidade, vestuário. 
Ao se debruçar sobre o enigma do homem, Morin chega à conclusão de que nem a comunicação, nem o símbolo, nem o rito são exclusividades do "homem sábio", tendo suas raízes plantadas em terreno muito distante na evolução das espécies (MORIN, 1975, p. 35). Também a sociedade, concebida como uma organização complexa de indivíduos baseada em competição e solidariedade, ao contrário do que se poderia pensar, parece ser um fenômeno muito comum na natureza e não configura uma conquista inteligente. Conforme afirma Morin, quando surge o sapiens, o hominídeo já é socius, faber e loquens.

A novidade que o 'sapiens' traz ao mundo não está, portanto, conforme se havia pensado, na sociedade, na técnica, na lógica, na cultura. Encontra-se, por outro lado, naquilo que até o presente fora considerado epifenomenal ou ridiculamente considerado indício de espiritualidade: na sepultura e na pintura (Ibid, p. 101).

Durante muito tempo limitamo-nos a admirar as realizações pictóricas das grutas de Altamira como um testemunho do nascimento da arte. No entanto, maior admiração deve causar a consciência de que essas pinturas, mais que meras representações artísticas, embora grandiosas em sua concepção e resultado, constituem o marco inicial da atividade inteligente da espécie humana. Primeiramente, essas realizações gráficas, repletas de significados simbólicos, podem ser consideradas uma forma de linguagem, capaz de relatar às gerações subseqüentes a história dos feitos ancestrais. Não é ainda uma linguagem escrita, mas já testemunha uma abstração, uma nova habilidade de exprimir a realidade, que pode ser definida como uma síntese, em imagens, de um pensamento que se reporta ao passado. Por outro lado, a intenção mágica contida nessas pinturas, ao procurar antecipar façanhas vindouras como forma de lhes garantir o sucesso, revela um processo de apropriação simbólica que se remete ao futuro.

Tendo o estudo das sociedades arcaicas mostrado que as representações artísticas podem estar ligadas a operações rituais, supôs-se que o ato de representar a caça destinava-se a propiciar sua posse em verdade. Daí a fidelidade figurativa dessa primeira grafologia que, com o tempo, no momento em que, pela evolução natural das habilidades humanas de subsistência, 
não existir mais essa dependência premente do ato de caçar, sofrerá uma esquematização em direção a uma visão mais intelectiva das imagens-símbolos.

Morin propõe compreender a linguagem mágica contida nas pinturas rupestres alicerçando-se no conceito do "duplo". A imagem já não seria uma simples figuração, guardando em si a presença do duplo do ser representado, o que possibilitaria uma ação sobre esse ser. Todo objeto tem, então, para o "homem sábio", uma dupla existência:

Por meio da palavra, do sinal, da inscrição, do desenho, esse objeto adquire uma existência mental até mesmo fora de sua presença. Assim, a linguagem já abriu a porta à magia: desde o momento em que toda e qualquer coisa traz imediatamente ao espírito a palavra que a identifica, essa palavra produz imediatamente a imagem mental da coisa que ela evoca e confere-lhe presença, ainda que ausente (MORIN, 1975, p. 107).

O que as figuras parietais nos revelariam seria a ligação imaginária com a realidade. A imagem, a palavra, o símbolo reapresentam ao espírito as coisas e seres do mundo exterior que, de certa forma, invadem o pensamento. Em contrapartida, o próprio pensamento invade o mundo exterior e, para recompor a nitidez da perspectiva, o indivíduo constrói o mito e a magia. Segundo relata Morin,

a partir de então, mitologia e magia serão complementares e estarão associadas a todas as coisas humanas, até mesmo as mais biológicas (morte, nascimento) ou as mais técnicas (a caça, o trabaIho); elas vão colonizar a morte e arranca-la do nada (ibid, p. 109).

A arte pode ser, portanto, aquilo que nos distinguiu das demais espécies, confirmando que o sapiens tornara-se capaz de abstrair de sua existência o momento presente para evocar um outro tempo existencial e uma segunda existência, fora da percepção empírica, uma presença no espírito sob a forma de imagem mental. A magia não elide a realidade de uma germinação do conhecimento artístico, ainda que com finalidade ritual e mística, uma vez que, diferente das demais espécies, o sapiens se torna não apenas portador do fenômeno estético, por inscrição genética, mas produtor desse fenômeno, por uma 
ação inteligente individual, fundamentada na técnica e na arte. A sepultura, por sua vez, mais que um simples enterro para proteger os vivos da decomposição de um corpo, revela uma nova consciência da sujeição inevitável que pesa, sobre todos, na passagem de um estado para outro. Tal pensamento parece transcender o momento presente, delineando os contornos de um sentido temporal no seio da mente humana.

A morte não só é reconhecida como fato, conforme a reconhecem os animais (que, além do mais, já são capazes de se "fazerem de mortos" para enganar o inimigo), não é somente sentida como perda, desaparecimento, lesão irreparável (coisas que o macaco, o elefante, o cão, o pássaro podem sentir), a morte também é concebida como transformação de um estado em outro estado (ibid, p. 102).

Ao mesmo tempo, surge a crença de que essa transformação resultará, após a vida, em uma outra existência, na qual deverá ser mantida a identidade do morto. Essa convicção parece indicar, segundo o pensamento de Morin, que o imaginário irrompe na percepção do real e que o mito brota na visão do mundo (ibid, p. 103). Todo um processo mitológico-mágico emerge no sapiens, que se mobiliza para enfrentar a morte e, ainda que reconheça a sua própria transitoriedade na Terra, procura afirmar, senão a perenidade da vida, ao menos uma possível transmortalidade.

Túmulos neandertalenses revelaram que, mesmo nesse distante período, os ossos sepultos achavam-se, por vezes, pincelados com ocre avermelhado que, ao que se supõe, era usado, também, para decoração do corpo humano. Tudo indica que havia uma preparação cuidadosa do féretro. O cadáver não era simplesmente abandonado em lugar ermo para livrar os vivos da visão da morte. Assim sendo, sepultar os ancestrais revestidos de suas insígnias pessoais, costume colocado em evidência pela descoberta de urnas funerárias intactas em pesquisas arqueológicas, parece ser a tradução do desejo humano de fugir a um destino inexorável e, preservando a identidade do morto, transcender o seu fim. Insinua-se a idéia de que é necessário reforçar a presença pessoal do morto, para que sua individualidade permaneça viva na memória dos demais. 
Os ritos da morte exprimem, reabsorvem e exorcizam o trauma provocado pela conscientização sobre a existência de um marco terminal inevitável. O homem não só recusa o seu fim, mas procura, de certa forma, vencer uma inaceitável extinção. Torna-se imprescindível, portanto, reafirmar a sua individualidade, para que ela permaneça viva além da vida. Assim sendo, seguindo adiante pelo caminho aberto por Morin, torna-se possível deduzir que transformar o corpo imposto pela ordem natural, vestindo-o, decorando-o, contrariando a disposição de suas formas e tornando-o único entre os demais, foi uma das maneiras que o sapiens -um ser invadido pelo imaginário e angustiado pela consciência da morte, sem nela querer acreditar- encontrou para se afirmar como indivíduo singular, demonstrando uma ilusória superioridade sobre a natureza que o concebeu mortal.

O estudo das sociedades arcaicas mostra que a decoração, o adorno e a pintura do corpo podem guardar valor de proteção e de sorte, estando ligados a crenças mitológicas e ritos religiosos, demonstrando, assim, que a consciência mística irrompera no cérebro humano. A recriação personalizada de disposições corporais inscreve-se, dessa maneira, no âmbito da magia, do mito, do ritual ou, de maneira mais generalizada, na amplitude das atividades sociais, embora possa satisfazer, por outro lado, a um prazer inventivo realmente estético.

Pela composição indumentária, o homem redefine sua realidade e, justapondo cores ou confrontando linhas, estabelece uma equivalência entre a pele natural e a forma por ele idealizada. Gera uma nova configuração estética para o corpo, combinando os ornatos e panejamentos que integrarão seus contornos. Constrói um jogo de efeitos entre a carne e os tecidos que, ora a ocultam entre pregueados e drapejamentos, ora a expõem entre fendas e cortes, como que desintegrando a imagem humana, para reconstruí-la com uma liberdade que só se permite ao artista.

A arte do vestir nasceu, portanto, com os primeiros homens e, mesmo entre as raras sociedades que não conheceram alguma forma de tecelagem, ou o emprego de peles e entrecascas como recursos para cobrir a nudez, haveria o que se pode 
interpretar como um sistema de vestuário. Pinturas corporais, cicatrizações, escarificações, tatuagens, ou o uso de contas, plumas, conchas e outros objetos análogos empregados como ornamentos, constituiriam códigos indumentários com funções comparáveis às das vestes modernas. O desejo de se afirmar como pessoa única, a sinalização de status social, a busca da sedução, a vaidade, a procura por regras estéticas para a valorização da aparência, sempre fizeram parte da natureza humana.

Como mostram Aranha e Martins, o mundo cultural resume-se em um sistema de significados, previamente determinados por outros, no qual até mesmo no terreno das emoções o indivíduo vê-se à mercê de normas preestabelecidas: o próprio corpo humano nunca é apresentado como mera anatomia, mas já é percebido envolto em panos, que traduzem interdições pelas quais é levado a ocultar sua nudez, em nome de valores que Ihe são ensinados (ARANHA e MARTINS, 1986, p. 8). A opção por determinadas construções vestimentárias dá-se em função de uma necessidade de auto-valorização da imagem, impulsionada, da mesma forma, por codificações sociais que infundem a crença de que a aparência reconstruída, na medida em que exiba sinais de status, poderá produzir um melhor reflexo pessoal sobre os demais.

Os papéis desempenhados na vida social, muitas vezes, podem ser definidos pela seleção das peças de vestuário organizadas sobre o corpo. Assim como o ator encontra apoio no figurino para a definição de sua personagem, os indivíduos servem-se das roupas para explicar seu lugar no mundo. Observam Castilho e Martins:

Nos mundos ilusórios criados pela moda, o sujeito entra em conjunção com determinados produtos aos quais são agregados valores subjetivos. São esses, por sua vez, que promovem a satisfação do sujeito em relação à sua identidade construída (2005, p. 30).

Deste modo, o uso de roupas ou ornamentações corporais pode ser considerado uma necessidade básica do ser humano, tão premente como as de abrigo, alimentação ou procriação. As composições vestimentárias organizadas sobre o corpo do indivíduo, revestem e redefinem suas configurações estéticas, 
contribuindo, além disso, para a definição de seu discurso social. Identifica Greimas o ato cotidiano de se trajar como uma tentativa realizada pelo indivíduo para, mediante a escolha e combinação das peças de seu vestuário, acrescentar algo de novo, diferente, à superfície corporal (GREIMAS, 1987, p. 80). A maneira pela qual ele dispõe suas vestes sobre si pode ser descrita como uma linguagem que, embora não verbalizada, transmite uma clara mensagem ao grupo social de pertencimento.

Assim sendo, se a moda, como a conhecemos na atualidade -enquanto culto à novidade e à fantasia, ao efêmero e ao instável- revela-se um processo relativamente recente e inseparável do surgimento das modernas sociedades ocidentais, o vestuário ou o adorno do corpo acompanham a história da humanidade, desde o seu amanhecer. Ao mesmo tempo em que facultam ao indivíduo uma experiência formal, criando uma outra realidade para sua aparência, o vestuário e a moda permitem-Ihe a adoção de uma linguagem vestimentária eloqüente e pessoal, a qual o auxilia a traduzir os sentimentos e saberes íntimos que deseja compartilhar com os demais. O vestir intervém no processo de percepção do corpo, agregando às suas formas valores capazes de desvelar as janelas do espírito, ao estabelecer uma espécie de contaminação entre o exterior e o interior de cada um.

Ao organizar as peças de vestuário em um conjunto simbólico, marcado por sutis diferenças que ressaltam sua identidade própria e intransferível, o indivíduo aciona o sistema da moda, fundamentado em um estímulo que leva à aceitação e à imitação de convenções grupais e um ímpeto oposto, de inovação na busca de destaque pessoal. A construção significante das roupas e os dizeres óbvios ou obscuros do corpo, revelando suas motivações mais profundas, podem delinear o trajeto histórico do indivíduo e o do grupo ao qual pertence. Esse processo ocorre em via de mão dupla e deixa no grupo, igualmente, marcas perceptíveis da personalidade de seus membros.

Uma pergunta que se faz presente diz respeito à constante mutabilidade da moda. De onde surge essa instabilidade de tendências que parece reger o fenômeno? Basicamente, o desejo de se trajar de modo semelhante ao grupo dá impulso 
à reprodução dos padrões vigentes em cada época, em determinado local. O indivíduo observa seu entorno e nele divisa a figura do "outro" e seu modo de vestir e se adornar, fazendo uma relação, ainda que em nível do inconsciente, das peças que ele possui para compor seu visual. Se o "outro" tem, também ele ambiciona ter. Mas, ao mesmo tempo, esse indivíduo não deseja se tornar apenas "mais um" entre os demais. Então, procura compor seu vestuário de maneira personalizada, acrescentando detalhes ou modificando formas. E o "outro", por sua vez, observando-o de maneira recíproca, nota tais acréscimos ou inovações, podendo incorporá-los às suas próprias roupas. É a absorção ou o descarte de propostas inovadoras que alimenta velozmente o moto contínuo da moda. A esse respeito lembram muito bem Castilho e Martins:

Para comunicar, os seres humanos trocam sinais. Esse fato significa que é impossível existir consciência de si mesmo e o estabelecimento de sua realidade se não em relação ao "outro". O ser humano possui uma natureza proeminentemente social; seu comportamento, sua personalidade, seu modo de pensar e de sentir suas necessidades - inclusive a de decorar-se - começam a ser explicáveis quando o percebemos suscetível à existência real ou imaginária de outros indivíduos. O "outro" é estímulo e ocasião de resposta $(2005$, p. 39).

No século $X X$, com o avanço dos estudos semióticos como campo de investigação científica voltada para a compreensão de todo e qualquer processamento de signos e significações, começou-se a perceber que o simbólico e o subjetivo permeavam a linguagem humana. Muitas vezes, os sinais visuais chegam a ser mais convincentes que o discurso falado. Somos impulsionados a estruturar e desenvolver sistemas que possam potencializar nossa comunicação e, com esse objetivo, procuramos dotar o nosso corpo de significações que acresçam vigor a nossas mensagens verbais. A investigação dessa gramática determinou, assim, que os olhares se voltassem sobre o físico, os gestos e seus significados. Da mesma forma, como a linguagem corporal amplia as possibilidades de comunicação, o dizer das roupas e adornos pode alargar os horizontes de informação. A sobreposição de peças vestimentárias ao corpo possibilita a sua 
reconstrução em diferentes volumes e formas, cujo significado pode ser traduzido em um novo repertório de valores.

Ao se conhecer que os atos e práticas corporais, assim como a maneira de compor seus trajes, constituíam elementos característicos de uma determinada cultura, definindo mesmo estilos de época e estereótipos indumentários regionais, o corpo passou a ser visto como um fantástico espaço constitutivo de relações sociais. Abandonando os conceitos simplistas de carne pecaminosa, da visão religiosa medieval, ou fora de trabalho, da lógica industrial, ele foi retomado em sua materialidade, como objeto de culto narcisista ou como elemento de ttica e ritual social (BAUDRILLARD, s.d., p. 139).

A perspectiva histórica projeta uma nova experiência sensorial do corpo, mostrando-o, hoje, em inegável evidência, realçado por artifícios e tratamentos de beleza estruturados em recorrentes considerações sobre o erotismo e a sexualidade. A busca por elegância e juventude transformou-o em objeto de cuidados constantes, parecendo ter se convertido na pedra angular das preocupações humanas. Conforme aponta Baudrillard

durante séculos fizeram-se esforços encarniçados para convencer as pessoas de que não tinham corpo (embora, por outro lado, nunca se tenham convencido disso); hoje teima-se sistematicamente em convencê-las do próprio corpo (ibid, p. 136).

Ainda que mergulhado, de certa forma, em uma trama de relações de poder que o dirigem e sujeitam, é a partir do estudo dessas mesmas formas de dominação política, social, sexual ou mesmo ideológica, e acima delas, que podemos encontrar o corpo lúdico que se expõe, livre, prazeroso, como campo do desejo, da sedução, e território intrigante a ser interrogado em seus múltiplos significados e simbolismos. Estamos, inegavelmente, na contramarcha da Idade Média.

Lembra-nos Becker que, embora o instinto de conservação seja comum a todos os animais, os homens so criaturas verdadeiramente miserveis, porque lograram ter conscincia da morte (BECKER, 1992, p. 242). O medo de morrer, inato e abrangente, leva-os a tentar transcender essa realidade, servindo-se de sistemas e símbolos heróicos, culturalmente constituídos (ibid, 
p. 13). Esses símbolos não devem envelhecer ou se consumir, para que seja possível elidir seus temores, dando-lhe a esperança de uma continuidade física indefinida.

Sabedora de sua mortalidade, a humanidade esforça-se por exorcizar esse aterrador fantasma, exercendo uma falsa autoridade sobre o tempo, na ingênua tentativa de conquistar o impossível. Burlando os sinais da idade, o homem hodierno procura vencer o aniquilamento físico, da mesma maneira que o tribal, pela pintura do rosto e do corpo, buscava transformar as configurações que lhe dera a natureza, na tentativa de demonstrar um poder hegemônico sobre suas leis.

Observa Clastres:

É, sem qualquer intermediário, o corpo que a sociedade designa como único espaço propício a conter o sinal de um tempo, o traço de uma passagem, a determinação de um destino (...) o corpo mediatiza a aquisição de um saber, e esse saber é inscrito no corpo (2003, p. 198).

Assim, o indivíduo contemporâneo empenha-se em construir para si, a exemplo de seus ancestrais, uma espécie de armadura capaz de afastar seus temores, não mais com tintas, ossos, presas, ou membros decepados aos inimigos, mas com as conquistas fantásticas da técnica, que parece ser capaz de remeter ao infinito a certeza da velhice e da morte. Um novo mito se cria, um novo culto é organizado, onde o próprio deus, preso a um código visual de signos, é consumido. Resume o problema Balandier, ao declarar que a razo cientfica retoma o sonho, a seu modo (BALANDIER, 1999, p.110).

A morte, esse desafio do desconhecido, esse absoluto fracasso que marca o limite extremo do humano, não é mais a grande provocadora de um imaginário do qual as crenças e as tradições tiraram seu vigor (ibid, p. 114).

Nesse processo de verdadeira sacralização do corpo, as leis da sociedade capitalista acabam por tudo reduzir a um valor de troca. Em uma luta incessante contra um inevitável enveIhecimento, o corpo se torna uma das formas do espetáculo de massa. Um verdadeiro ritual é montado, para que o novo ídolo seja consumido sob o comando das decisões da moda, 
fenômeno que se encontra profundamente inserido em nosso contexto cultural, onde as relações sociais determinam formas específicas de produção, circulação e consumo de seus significados. Como resultado, o corpo se submete à estética vigente, que propõe formas particulares de construí-lo e discipliná-lo no modelo prescrito, ou de celebrá-lo como metáfora do prazer, a partir de significados culturais e subjetivos de beleza.

Mas esse balizamento imposto pela moda, que parece moldar de maneira uniforme o estilo de um grupo social, não anula a conscientização do indivíduo quanto ao significado profundo de suas atitudes em relação ao seu corpo e ao que ele veste, na construção de uma personalidade reconhecível e singular. Não apaga, também, a importância do impulso estético que, de uma forma ou de outra, rege o fenômeno, levando o indivíduo a recriar, nos aspectos formais das roupas, o direcionamento artístico que preside seu tempo. No diálogo que se estabelece com os movimentos da arte ou nos padrões de beleza compartilhados, um processo de criatividade se desenvolve permitindo a cada um a expressão de seu gosto pessoal, ao mesmo tempo que possibilita um aprendizado estilistico.

De acordo com a proposição de Read, a arte no apenas algo que se encontra nos museus e galerias de arte, ou em velhas cidades como Florena e Roma. A arte, como quer que a definamos, est presente em tudo o que fazemos para agradar aos nossos sentidos (READ, 1958, p. 28). Procurando reiterar essa afirmação, o autor define um artista não somente como um homem que pinta quadros mas igualmente um homem que faz msica, poesia, ou mveis at mesmo sapatos e vestidos (ibid, p. 29). De fato, todas as manifestações artísticas apresentam como elemento comum uma determinada organização formal, ou seja, uma configuração particular na interpretação do espaço, que convida os sentidos a uma resposta estética. Em seguimento, deduz-se que na sociedade pluralista em que vivemos não é possível uma resposta única sobre o que seja arte.

Quando Duchamp, no início do século passado, apresentou ao público seus ready-mades, em protesto contra o pensamento tradicional que colocava a arte em um pedestal, provocou uma radical revolução dos conceitos estabelecidos. O 
movimento Dada, do qual o citado artista foi um dos pilares, ao contestar de modo absoluto valores anteriormente aceitos, coloca em crise a toda a cultura, a começar pela própria arte, que deixa de ser um modo de produzir valor. Com o Cubismo fora definida uma nova estrutura formal, mas a arte prosseguia como pesquisa cognitiva, mantendo sua tradição de produção de objetos de valor, porque na sociedade burguesa o objeto mercadoria, a mercadoria riqueza, a riqueza autoridade e po$\operatorname{der}(A R G A N, 1998$, p. 355). As primeiras objeções a esse racionalismo surgiram dentro do próprio movimento. Duchamp cria sua Marie, que não é um quadro nem um objeto, mas um mecanismo de lâminas com imagens superpostas e, em sucessão, expõe um mictório, assinando-o com o nome aleatório Mutt. Colocar uma assinatura em um objeto industrial significava que, embora tal objeto não possuísse valor artístico intrínseco, esse the era agregado a partir do juízo formulado pelo sujeito (ibid, p. 358).

Para Argan, a arte é um modo de fazer perfeito e exemplar, produzindo, consequentemente, objetos que seriam verdadeiros modelos de objetualidade geral e estariam longe de uma submissão ao domínio da técnica. Caso assim não fosse, a história da arte seria sempre a do academicismo, da tradição das belas-artes, ao contrário de ser a busca de um sistema de todas as relações possíveis, o que permite a inserção das obras em um amplo contexto histórico, criando um denominador comum entre o fazer artístico e as demais atividades do homem. Assim sendo, expressão de novos tempos, em que os campos da arte e a técnica têm suas fronteiras cada vez mais indefinidas, a moda parece assumir condições de figurar entre as demais vertentes artísticas. A exemplo de qualquer uma delas, também a arquitetura indumentária procura soluções para problemas de equilíbrio, volumes, linhas, cores e ritmos. Seus criadores trabalham com uma medida de espaço, ou seja, com uma forma. Igualar-se-ia em importância, pois, o fenômeno, às chamadas "artes puras", já que, como acentua Durand, considerar ou no arte uma prtica cultural e/ou artesanal qualquer, em Itima instncia, uma questo de classificao, ou seja, de hirarquizao de prticas humanas e daqueles que as executam (DURAND,1988, 
p. 123).

No século passado, as vanguardas enquadraram a arte em uma nova ótica, repensando-se, nesse terreno, o vestuário e a moda com suas formas, materiais e sistemas de produção. Criou-se, assim, uma profunda sinergia arte-moda, dando origem à multiplicação de obras que comprovam o mútuo interesse entre os dois campos. Exemplo disso é o trabalho de Andy Warhol, expoente da Pop Art, pintor, fotógrafo, escritor, editor do magazine Interview, produtor de televisão e cineasta que, tendo se dedicado à documentação objetiva dos fetiches-símbolos da civilização de consumo, personificou a abolição de fronteiras entre o objeto e a arte e, consequentemente, entre ela e a moda. Tendo começado sua carreira nas revistas Vogue, Glamour e Harpers Bazaar, como artista comercial, em 1957 assinou a instalação das vitrinas da Maison Nina Ricci. E, reforçando o reconhecimento do fenômeno, em 1975 apresentou para a exposição Fashion as Fantasy a obra Composite Dresses, conjunto de roupas montadas a partir de recortes de criações de famosos costureiros, como Yves Saint-Laurent, Halston, Valentino e Oscar de la Renta (MULLER, 1999). Muitas contribuições para a moda fez ainda o reconhecido artista, desde material para publicidade até roupas em papel serigrafado, realizando uma real integração entre as duas formas de expressão.

Embora alguns estudiosos sublinhem primordialmente os efeitos negativos que as novas descobertas tecnológicas e o desenvolvimento da produção industrial podem desencadear sobre o universo criativo, arte, tecnologia e métodos de industrialização vêm caminhando cada vez mais unidos. A expressão artística espraia-se por maiores áreas, usando mais, em contrapartida, os achados das ciências aplicadas. Do mesmo modo que Delaunay incorporava cores e contrastes característicos de suas pinturas a propostas têxteis, as instigantes roupas desenhadas pelos futuristas, com suas movimentadas linhas e estridentes matizes, refletiam o mesmo entusiasmo poético que sentiram ao recriar, nas telas, a mecânica das formas e o dinamismo da máquina. Outros estilistas reproduziam na moda motivos da Op Art, como o fez Jesus Rafael Soto, ao transferir as ilusões óticas de sua arte para as faces femininas, por meio 
dos brincos pendentes que desenhou (ANNOSCIA et al, 1997, p. 661). Muitos outros artistas têm integrado o mundo das artes ornamentais, desenhando jóias ou inspirando as criações de estilistas. Assim, enquanto propostas espaciais invadiam as passarelas de Courrèges e Cardin, o artista plástico Lúcio Fontana materializava suas space-ages-ideas em braceletes e anéis de ouro e prata. Por outro lado, os braceletes e telas fendidas de Fontana, por meio das quais o artista procurava evadir-se simbólica e materialmente da superfície plana, motivaram a criação da coleção de trajes idealizados pela estilista Milla Schön (ANNOSCIA et al, 1997, p. 662).

O mundo da moda, por diversas vezes, celebrou as obras de conhecidos artistas plásticos. Yves Saint-Laurent criou vestidos inspirados nos desenhos geométricos de Mondrian e saias que reliam as propostas cubistas de Picasso; Versace usou modelos futuristas em suas criações de 1989/90 e Valentino buscou motivos da Secessão Vienense para desenvolver seus croquis. Esse tipo de troca entre os campos específicos de atuação de cada área é típico da evolução interdisciplinar das artes, cancelando qualquer ordem hierárquica que possa ter prevalecido em tempo anterior.

Inúmeros pintores, como Monet, Renoir, Toulouse-Lautrec, Sargent e Klimt construíram seus melhores trabalhos pintando a figura humana e seus trajes. Klimt, em especial, parecia fascinado pelas roupas e chapéus de alta costura usados pelas mulheres vienenses e retratava suas modelos em magníficas vestes de erótica opulência e lânguida elegância, em obras que expressavam o estilo floral do Art Nouveau. Na tela "O Beijo", que se tornou um dos mais famosos ícones da corrente, o vestido da mulher representada entre formas geométricas em vários tons de dourado e ornamentos estelares, como que realiza uma fantasia sensual do pintor de envolvê-la num torvelinho precioso de cintilações e esplendores.

São incontáveis os artistas que privilegiaram o corpo humano e suas vestes em telas rememoráveis. Mas, como salienta Dorfles, mesmo o indivíduo mais prosaico e simples realiza, com a composição de seu vestuário, uma opção artística que pode se limitar a uma mera sugestão ou atingir ao paroxismo 
do desejo de auto-construção da imagem. Em qualquer hipótese, essa preferência formal reflete uma vontade precisa, não apenas de diferenciação social, mas de reconhecível empenho estético (ECO (org), 1989, p. 69).

Se, ao longo da história da arte, os corpos fizeram parte das telas dos pintores de forma importante e recorrente, o vestir fez com que as telas dos trajes se tornassem parte desses corpos, em uma correspondência lúdica e irrecusável. Hoje, as fronteiras entre a moda e a arte borram-se e se liquefazem, e aquilo que era considerado frívolo e periférico ocupa lugar de destaque no terreno artístico. Desse modo, a máscara que se sobrepõe à face, o vestuário, passa a ser um dos principais elementos a retratar o pensamento estético de um tempo e, por suas relações significantes com o corpo e suas ocultas aspirações, traduz a forma idealizada do eu.

\section{Referências}

ANNOSCIA, E. et al. Art A World History. London: Dorling Kindersley, 1997.

ARANHA, M.L.A. e MARTINS, M.H.P. Filosofando: introdução à filosofia. São Paulo: Moderna, 1986.

ARGAN, G. C. Arte Moderna. São Paulo: Companhia das letras, 1998.

BALANDIER, G. O Ddalo Para finalizar o sculo XX. Rio de Janeiro: Bertrand Brasil,1999.

BAUDRILLARD, J. A sociedade de consumo. Rio de Janeiro: Edições 70, s.d.p.

BECKER, E. La luccha contra el mal. México: Fondo de Cultura Económica, 1992

CATILHO, K. e MARTINS, M.M. Discursos da Moda; semitica, design e corpo. São Paulo: Editora Anhembi Morumbi, 2005.

CLASTRES, P. A sociedade contra o Estado. São Paulo: Cosac e Naify, 2003.

DURAND, J.C. Moda, luxo e economia. São Paulo: Babel Cultural, 1988. 
ECO, U. (org.) Psicologia do vestir. Lisboa: Assírio \& Alvim,1989.

GREIMAS, A. De la imperfection. Périgueux: Fanlac, 1987.

MORIN, E. O enigma do homem. Rio de Janeiro: Zahar Editores, 1975.

READ, H. A educa pela arte. São Paulo: Martins Fontes, 1958.

\section{MIRIAM DA COSTA MANSO MOREIRA DE MENDONÇA}

Doutora em Ciências Sociais pela Pontifícia Universidade Católica de São Paulo; Mestre em Ciências da Comunicação pela Escola de Comunicação e Artes da Universidade de São Paulo; Especialista em Arte-Educação pelo IA/ UFG. Coordenadora do Curso de Graduação em Design da Moda da Faculdade de Artes Visuais da Universidade Federal de Goiás. Professora de História da Moda e Design. E-mail: mcostamanso@uol.com.br 